\title{
Estimation of forest cover change using Sentinel-2 multi-spectral imagery in Georgia (the Caucasus)
}

\author{
Giorgi Mikeladze ${ }^{(1)}$, \\ Alexander Gavashelishvili ${ }^{(1)}$, \\ Ilia Akobia (2), \\ Vasil Metreveli ${ }^{(1)}$
}

\begin{abstract}
Our objective was to use Sentinel-2A multispectral data in order to cost-effectively detect change in forest cover in Georgia (the Caucasus). Generalized additive models (GAMs) were used to fit forest cover measures to Sentinel-2A spectral band values modified using different topographic correction methods. Canopy closure (calculated from upward-looking fisheye photographs taken beneath forest canopy) was the best forest cover measure accounted for by the Sentinel-2 spectral data that were topographically corrected using the Minnaert Correction $\left(R^{2}=0.882\right)$. Spectral bands best explaining canopy closure were Band 3 (Green), Band 8 (NIR) and Band 12 (SWIR). Our model is able to reasonably detect spatial and temporal changes in canopy closure, even in highly rugged terrain and diverse vegetation cover, and it has potential to be improved to the extent that it can be applied by managers of natural resources. Based on free open source applications in combination with cheap gadgets our approach might play an important role in monitoring the forests of countries with low economic indicators.
\end{abstract}

Keywords: Generalized Additive Models, Forest Cover, Satellite Imagery, Sentinel-2, Fisheye, Topographic Correction

water balance, carbon accumulation and biodiversity (Asner et al. 2009a).

Identifying disturbances in forest cover for large areas is an important task not only to study forest ecosystems but also to monitor anthropogenic impacts. Today remote sensing is the most practical and accurate tool for determining changes in forest cover at the regional level (Asner et al. $2009 \mathrm{~b}$ ). With the development of satellite technology, the quality of mapping of forest canopy cover and the detection of deforestation and forest disturbance has significantly improved (Achard et al. 2007). Free remote sensing data (e.g., Landsat, MODIS, Sentinel) makes it possible to create monitoring systems of regional or planetary scales. At present global forest monitoring systems are mainly based on 30-meter resolution data from Landsat satellites (Asner et al. 2009b, Hansen et al. 2010, 2013).

Changes in forest cover are not always distinguished by modern monitoring systems based on remote sensing data. The fact is that in global models it is not always possible to distinguish forest degradation because the density and structure of trees are difficult to interpret in satellite images of medium resolution (Köhl et al. 2009). Difficulties also arise with the use of topographic image correction in rugged terrain because of topographic illumination effects (Liang 2005, Tan et al. 2013). Because topographic effects may have dramatic impacts on the outcomes of time series and change detection studies, topographic correction of remotely sensed imagery over mountainous regions in these studies is critical (Liang 2005). Also, the limitation in the interpretation of the forest arises due to its vertical structure, as it is extremely complicated to detect degradation under the closed canopy cover using optical satellites (Köhl et al. 2009). The accuracy of the models also depends on the capabilities of the satellite data. For example, Sentinel-2 provides better models of forest cover (CC), effective cover (ECC) and leaf area index (LAI) in lowland boreal forests than Landsat 8 (Korhonen et al. 2017).

Mapping of forest cover using remote sensing is usually performed by land classification into forest and non-forest. However, the maps derived from satellite data depend on the definition of the forest, mainly on the threshold of tree cover parameters, above which the territory is identified as a forest (Sexton et al. 2015). An alternative approach is continuous surface that can represent areas of heterogeneous tree cover better than models based on discrete interpretation (Hansen et al. 2002). To assess the ecological characteristics of the forest, canopy closure is one of the most useful determinants of its structure and biophysical attributes such as tree density and health (Chopping et al. 2012). Canopy closure is also an important measure to estimate the distribution of trees on a global scale (Crowther et al. 2015). Hemispherical photography is one of the many ways to measure canopy closure and obtain various biophysical parameters (Fournier et al. 2003, Chianucci \& Cutini 2012). Models of solar radiation transmittance through the canopy are widely used in remote sensing (Schleppi \& Paquette 


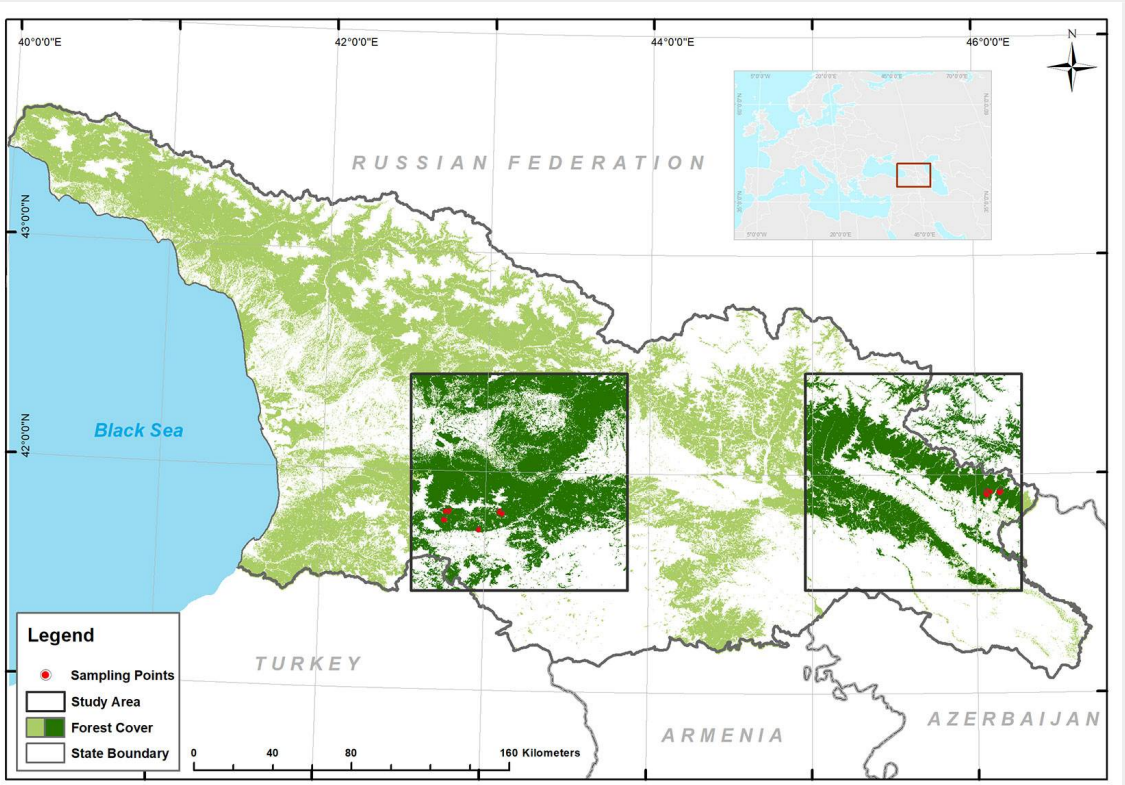

Fig. 1 - Sampling plots for forest cover parameters and the extents of two Sentinel images intersecting Central Georgia (at left) and Eastern Georgia. The map is projected to UTM Zone 38N; WGS: 1984.

2017) as the canopy structure provides important information on the functions and dynamics of the forest ecosystem (Brusa \& Bunker 2014). Although there have been many studies of calibrating forest cover parameters (including canopy closure, LAI) against remotely sensed spectral bands and vegetation indices derived from these bands, a set of spectral predictors for each of the forest cover parameters substantially varies with sensors, forest structure and geography (Meyer et al. 2019).

In this study we used digital hemispherical photography in combination with remote sensing for the first time in the Caucasus. The main goal of this study was to evaluate the possibility of creating a forest monitoring system based on freely available software and satellite multispectral images of Sentinel-2 for heterogeneous and rugged areas of Georgia and Caucasus. More specifically we attempt to find a quantitative indicator of forest cover that can be best explained temporally and spatially by the Sentinel-2 multispectral bands through testing various topographic correction methods. Maps derived from our model will help efficiently monitor land surface change, especially that of forest cover.

\section{Materials and methods}

\section{Study area and sampling}

Our objective was to use Sentinel-2A multispectral data in order to detect change in forest cover. To maximize statistical representativeness of our sample (i.e., variability of response and explanatory variables) we sampled old-growth forests, the tree line (i.e., the elevation above which trees fail to grow), forests with logging operations and ecological succession processes. We conducted our fieldwork in 2018 between July 7 and August 15 in two regions: Central Georgia including coniferous and mixed forests and Eastern Georgia including deciduous forests (Fig. 1). Forest cover parameters (Tab. S1 in Supplementary material) were measured within $20 \times 20 \mathrm{~m}$ plots whose sides were oriented parallel to the true north-south axis. The plots were distributed evenly across 4 categories of tree cover percentage: $0-25 \%, 25-50 \%$, 50-75\%, $75-100 \%$. The tree cover percentage was estimated visually by two foresters on the field.

During the most stable vegetation period from July to early September, we were able to process a total of 80 plots: 45 plots in Central Georgia and 35 plots in Eastern Georgia (Fig. 1). More specifically, 20 plots at Otskhora, 5 plots at Kurtskhana (tributaries of Abastumani River), 5 plots at Tsveruknis Ghele, 15 plots at Bagebis Ghele (tributaries of Mtkvari River) and 35 plots at Kabali River (a tributary of Alazani River). The plots were dominated by any of the following species: Abies nordmaniana, Picea orientalis, Pinus kochiana, Carpinus betulus, Fagus orientalis, Quercus iberica, Dryopteris filix mas, Festuca sp., Rubus caucasicus, and a plant community of subalpine meadows (a mixture of grassland, Rhododendron caucasicum and stunted Betula spp.). The species dominance in the plot was assigned by either the tree basal area or the percent vegetation cover: the tree species, whose basal area was the largest in a plot, was considered as dominant in the plot, while in a tree-less plot the plant species or community that had the largest percent cover, was considered as dominant.

\section{Forest cover parameters}

The ratio of the area of canopy to the sky was measured using a mobile phone (Huawei $\mathrm{P9}{ }^{\circledR}, 12 \mathrm{MP}$ ) with AMIR photo $180^{\circ}$ Fisheye Lens and the software Gap Light Analyzer 2.0 (Frazer et al. 1999). The hemispherical images were taken in the center of the study plot, normal to the horizontal (i.e., photographs oriented parallel to the horizontal) at a height of $30 \mathrm{~cm}$ above ground under the diffuse sky (i.e., uniformly overcast sky, or sky near sunrise or sunset). All images containing such obstructing objects as boulders, cliffs, fallen trees or hills and peaks were excluded from further processing. The field of view of each image was reduced to $90^{\circ}$ in order to (i) reduce distortions and noise near the edge and (ii) remove shaded fractions introduced by the steepest (i.e., $38^{\circ}$ ) of the slopes in our data set. The blue channel of each image, which maximizes the contrast between sky and canopy, was chosen. Then the separation of pixels within each image into sky and non-sky classes was performed by visually (i.e., subjectively) selecting a threshold value for each hemispherical image, which best separated the sky pixel from canopy. Lastly, the proportion of canopy pixels was computed for each image (hereafter the canopy closure). This entire procedure was performed separately by three image interpreters, and the mean of the three canopy closure values was used for each of the images.

The tree diameter and basal area was measured at $1.3 \mathrm{~m}$ above ground, at the breast height (DBH), using forestry caliper (Nestle forestry caliper Waldmeister, Dornstetten, Germany). Individual basal areas were summarized to calculate the total basal area of a study plot. The tree height was measured using Suunto $\mathrm{PM} 5 / \mathrm{SPC}^{\oplus} \mathrm{Cli}$ nometer (Vantaa, Finland) and averaged in a study plot.

\section{Satellite imagery}

For remotely sensed spectral data we used the already orthorectified Sentinel-2A imagery (available at https://scihub.copern icus.eu/dhus/\#/home), which consists of 13 bands with three different resolutions (10, 20 and $60 \mathrm{~m}$ ). Because of extensive cloudiness in the sentinel imagery for our entire study period we had to use two scenes: one acquired on July 1, 2018 for Eastern Georgia and the other one acquired on $\mathrm{Au}$ gust 28, 2018 for Central Georgia. Due to the limited availability of cloud-free imagery difference in time between sampling forest cover parameters and Sentinel image acquisition varied between 6 and 45 days (mean $\pm S D=25.225 \pm 13.153)$. The sampled and spectral data (Tab. S1 in Supplementary material) were mapped and organized into a data frame using QGIS Desktop 3.4.5-Madeira software package (QGIS Development Team 2019).

Most of the territory of Georgia, including our study area, is substantially rugged, which greatly affects the interpretability of 
satellite images. Therefore, in addition to atmospheric correction, we also applied topographic correction. Sen2Cor, which is a processor for Sentinel-2 Level 2A product generation and formatting, was used to perform atmospheric and cirrus correction of Top-Of-Atmosphere Level $1 \mathrm{C}$ input data. Bottom-Of-Atmosphere Level $2 \mathrm{~A}$ reflectance images were created using the following parameters: solar zenith angle, sensor view angle, relative azimuth angle, ground elevation, visibility and water vapor. All parameter values were derived from image metadata. Four topographic correction methods were tested: (i) topographic effect correction through the Sen2cor radiometric correction processor (hereafter, Sen2cor-corrected Sentinel bands); (ii) the Cosine Correction (hereafter C-corrected Sentinel bands - Teillet et al. 1982); (iii) the Minnaert Correction (hereafter Mcorrected Sentinel bands - Smith et al. 1980, Gao \& Zhang 2009); and (iv) the Normalization Method (hereafter N-corrected Sentinel bands - Civco 1989). For data processing we used SAGA-System for Automated Geoscientific Analyses. The most accurate effect of topographic correction is reached when using DEM and multispectral imagery at the same resolution (Kawata et al. 1988, Goyal et al. 1998), we used SRTM with $30 \mathrm{~m}$ grid size, available from USGS data portals. Unfortunately, a more detailed DEM was not available in our study to match with $10-\mathrm{m}$ and $20-\mathrm{m}$ spatial resolutions of our spectral data. The selected SRTM30 DEM for the study area was downloaded from free data portals (source: United States Geological Surveys - https:// earthexplorer.usgs.gov). The DEM contained errors in the form of spikes and gaps (elevation data outliers). For correction, we applied a $3 \times 3$ median filter using SAGA tools.

\section{Model development}

Generalized additive models (GAMs) were used to fit forest cover parameters to Sentinel-2A spectral band values using the "mgcv" package (Wood 2011) in R version 3.5.2 (R Core Team 2018). The possible effects of difference in time between sampling forest cover parameters and Sentinel image acquisition were also estimated. We used GAMs because without any assumptions they are able to find nonlinear and non-monotonic relationships, and have been successfully used in satellite-based canopy cover estimation (Halperin et al. 2016). GAMs were fitted using a Gamma family with a log link function, a Gaussian family with an identity link function and a binomial family with a logit link function. The binomial family was used for proportion response variables. Penalized thin plate regression splines were used to represent all the smooth terms. The restricted maximum likelihood (REML) estimation method was implemented to estimate the smoothing parameter because it is the most robust of the available GAM methods (Wood 2011).

Model and variable selection were performed by exploring all possible subsets of predictor variables, where pairwise correlations between variables were less than 0.9. To get subsets of predictor variables, thousands of variable combinations were generated using the "gtools" package for $\mathrm{R}$ (Warnes et al. 2015). The predictive power of the models was evaluated through a leave-one-out cross-validation. The crossvalidation of thousands of models was handled through R's parallelization capabilities (Weston 2017, 2018). The best models were selected by the mean squared error. We also checked concurvity between model terms and between each term and the rest of the model using the "mgcv" package. Akaike's Information Criterion (AIC) is generally used as a means for model selection. However, we preferred cross-validation for model selection because AIC a priori assumes that simpler models with the high goodness of fit are more likely to have the higher predictive power, while cross-validation without any a priori assumptions measures the predictive performance of a model by efficiently running model training and testing on the available data.

All gridded predictor layers (raster layers) were resampled to a resolution of $10 \mathrm{~m}$ using the nearest-neighbor assignment technique of QGIS Desktop 3.4.5-Madeira. The best forest cover model was predicted to the raster layers using the raster package (Hijmans 2016) in $\mathrm{R}$ version 3.5.2. To produce the final maps, the gridded estimates of the best forest cover parameter and their standard errors were masked with the forest cover developed for National Forest Agency (NFA) in 2015-2016. The NFA forest cover is defined as a grid of 0.5 ha cells where crown cover is $>20 \%$.

From gridded estimates and standard errors, we derived statistically significant dif- ferences in forest cover ( $p$-value $<0.05$ ) between July 1, 2018 and August 5, 2016 and between August 28, 2018 and August 14, 2015 for the Sentinel-2A scenes of Eastern Georgia and Central Georgia, respectively. Appendix 1 in Supplementary material contains the main $\mathrm{R}$ codes and the data set used in this study.

\section{Model validation}

Finally, we tested and compared the accuracy of detecting tree loss between our model and the maps produced by Global Forest Watch (GFW - http://www.globalfor estwatch.org/map). To do so, we used a $1.38 \times 2.44 \mathrm{~km}$ grid of $10 \times 10$ meter plots that were classified into those where percentage of tree loss from 2016 through 2017 was $\geq 5 \%$ and those where the loss percentage was less (source: Agency of protected area). There were 6032 plots with $\geq 5 \%$ tree loss (hereafter test plots) in this grid that covered an area located in Borjom-Kharagauli National Park (Central Georgia). Based on loss of tree cover on the GFW maps and statistically significant loss in forest cover of our model, we checked what portion of the test plots was detected by our and GFW models. We used this qualitative approach because a relevant quantitative measure of forest cover in the test area was not available to test our model. The altitudinal range of the test plots were from 1256 to $2113 \mathrm{~m}$ a.s.l. (mean $\pm S D=1613 \pm 162$ ), while their slope range in degrees varied from o to 67.1 (mean \pm SD $=$ $28.2 \pm 8.0$ ). Tree density in these plots varied from o to 0.8 (mean \pm SD $=0.44 \pm 0.32$ ). Canopy structure, vegetation types and diversity were much the same as in the training plots.

\section{Results}

Based on the exhaustive cross-validation procedure GAMs fitted to the canopy closure performed much better than those fitted to the other forest cover parameters (i.e., tree cover percentage defined by foresters on the field, total basal area, and tree average height). No more than $70 \%$ in the variation of the other forest cover measures could be explained by GAMs (Tab. S2 in Supplementary material). The best model of the canopy closure was the one that was fitted to M-corrected three spectral bands using a binomial family with a logit link function for proportion data (Tab. 1, Tab. 2, Fig. 2, Fig. 3 - see also Fig. S1 and

Tab. 1 - The diagnostics of the canopy closure models derived through different topographic corrections of Sentinel-2 bands. (MSE): Mean squared error; (Dev. Expl.): explained deviance; (AIC): Akaike's Information Criterion; (df): degrees of freedom.

\begin{tabular}{|c|c|c|c|c|c|c|c|}
\hline $\begin{array}{l}\text { Topographic } \\
\text { correction }\end{array}$ & $\begin{array}{c}\text { Cross-validation } \\
\text { MSE }\end{array}$ & $\begin{array}{l}100 \% \text { range limits } \\
\text { of residuals }\end{array}$ & $\begin{array}{l}95 \% \text { range limits } \\
\text { of residuals }\end{array}$ & $\mathbf{R}_{\text {adj }}^{2}$ & $\begin{array}{l}\text { Dev. Expl. } \\
\text { (\%) }\end{array}$ & AIC & df \\
\hline Sen2cor & 279.332 & $-35.676-17.838$ & $-20.073-13.533$ & 0.864 & 88.6 & 4119.893 & 26.078 \\
\hline Cosine & 258.328 & $-35.274-36.425$ & $-15.830-22.141$ & 0.819 & 84.7 & 5366.458 & 26.133 \\
\hline Minnaert & 178.620 & $-24.894-14.952$ & $-16.973-14.358$ & 0.882 & 89.8 & 3736.264 & 25.351 \\
\hline Normalization Method & 232.788 & $-33.086-38.060$ & $-23.560-16.510$ & 0.815 & 83.5 & 5734.853 & 25.935 \\
\hline
\end{tabular}


Tab. 2 - Summary of the generalized additive model (GAM) analysis for modeling the canopy closure (FEYE) as forest cover measure fit to Sentinel-2A spectral band values. $(n)$ : sample size; $(s())$ : spline smooth function; (edf): estimated degrees of freedom; $(P)$ : significance of terms. See Tab. S1 in Supplementary material for the description of variables.

\begin{tabular}{|c|c|c|c|c|c|}
\hline $\mathrm{n}$ & Variable term & edf & $\mathbf{P}$ & $\begin{array}{l}\text { Goodness } \\
\text { of fit }\left(\boldsymbol{R}^{2}{ }_{\text {adj }}\right)\end{array}$ & $\begin{array}{l}\text { Deviance } \\
\text { explained }\end{array}$ \\
\hline \multirow{4}{*}{80} & $s(\mathrm{~B} 03)$ & 8.106 & $<2 e-16$ & \multirow{4}{*}{0.882} & \multirow{4}{*}{$89.8 \%$} \\
\hline & $s(B 08)$ & 7.845 & $<2 e-16$ & & \\
\hline & $s(B 12)$ & 8.033 & $<2 e-16$ & & \\
\hline & Intercept $=-16.477$ & - & 0.00106 & & \\
\hline
\end{tabular}

Fig. S2 in Supplementary material). In addi- bands had the greatest goodness of fit, the tion to the lowest cross-validation error, least complexity and the shortest residual the relationship between the canopy clo- range. sure and the M-corrected three spectral Each of the four topographic correction methods suggested the same set of three bands best explaining variation in the canopy closure. These were Band 3 (Green), Band 8 (NIR) and Band 12 (SWIR). Band 8 was generally positively correlated with the canopy closure, while Band 3 and 12 were generally negatively correlated (Fig. 2). The magnitude of model fit for topographic correction in decreasing order was as follows.

Absolute difference in time between sampling forest cover parameters and Sentinel image acquisition did not have a considerable effect on absolute values of residuals $\left(R^{2}=0.0022\right.$, adjusted $R^{2}=-0.01061, p$-value $=0.68$ ). Difference in location and timing between the two scenes also did not have effect on the model. Some land surface features such as high cornfields, deep wa-
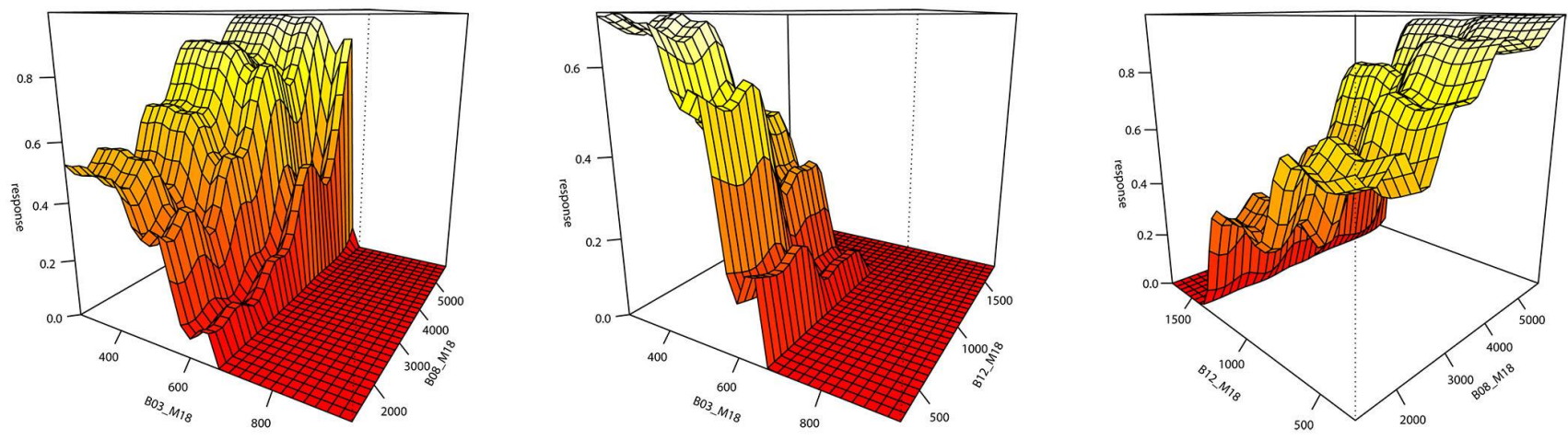

Fig. 2 - GAM-fitted relationships of the canopy closure (FEYE) in fractions and Sentinel-2A spectral bands in reflectance values $\times 10,000$. Band suffix M18 stands for M-corrected band acquired in 2018.

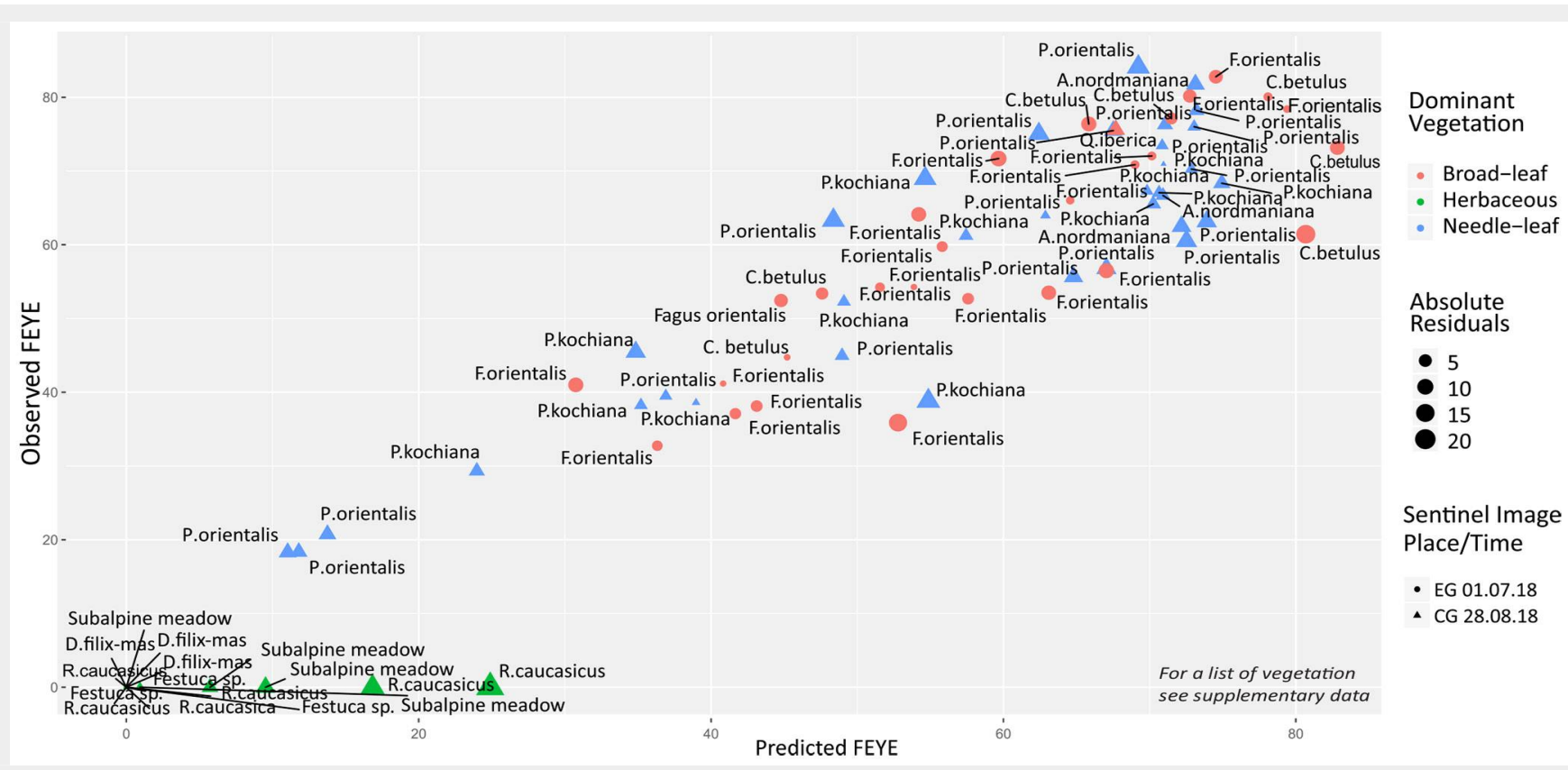

Fig. 3 - Scatter plot of fitted and observed FEYE values: the canopy closure (FEYE) GAM-fitted to M-corrected reflectance values of Sentinel-2A, using the REML smoothing parameter estimation (adjusted $R^{2}=0.882$ ). Graph points, labeled with dominant plant species, represent study plots whose color, size and shape indicate dominant vegetation cover, absolute residuals and Sentinel image acquisition place-date, respectively. The tree species, whose basal area is the largest in a plot, is considered as dominant in the plot, while in a tree-less plot the plant species or community, that has the largest percent cover, is considered as dominant. 
Fig. 4 - Testing the model accuracy of detecting tree

loss from 2016 through 2017 in Borjom-Kharagaul National Park (Central Georgia). The map is projected to UTM Zone $38 \mathrm{~N}$ WGS: 1984.

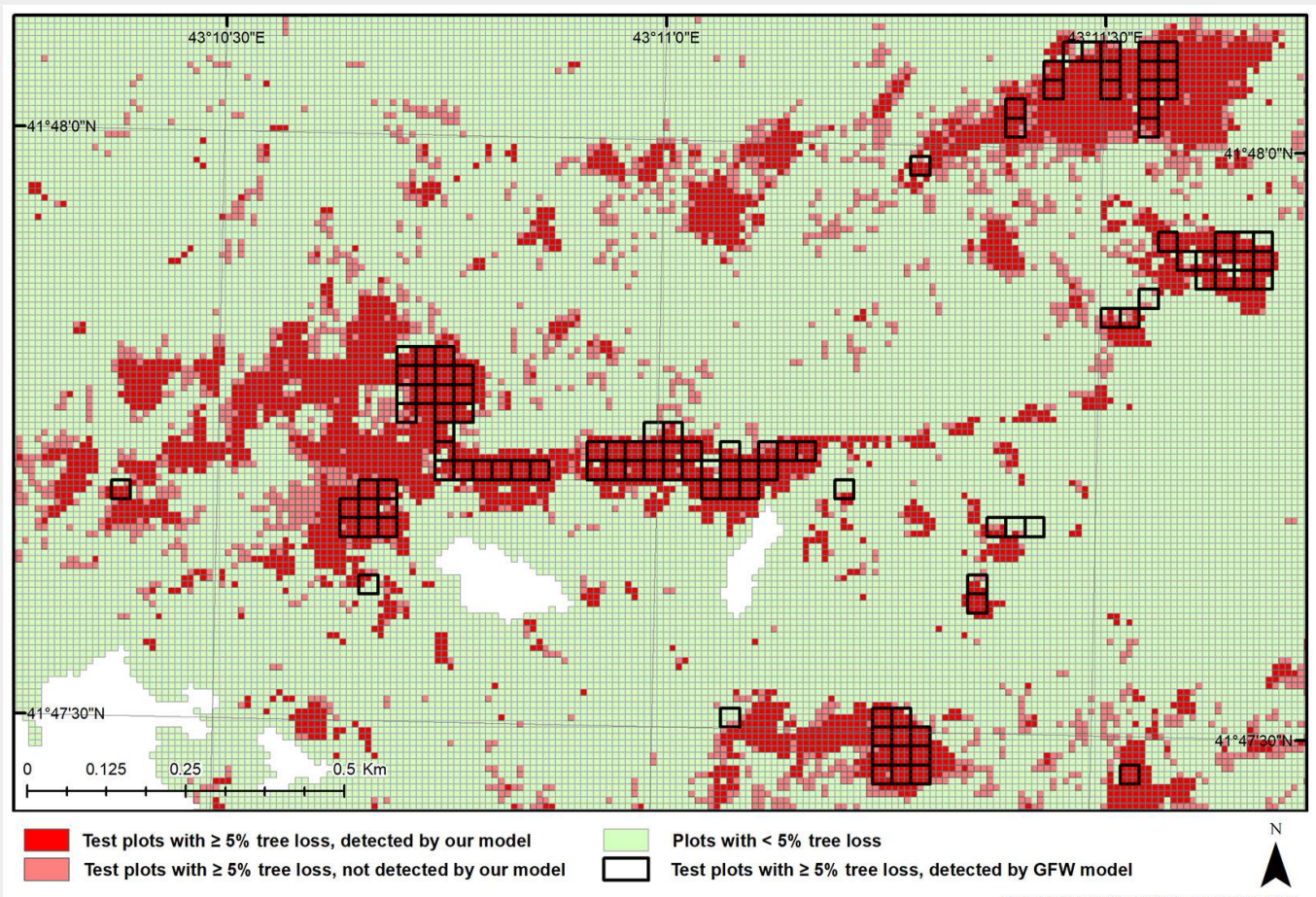

ter bodies, some wetlands and orchards showed FEYE as high as forests (up to $80 \%$ ). However, these features were masked out by the NFA forest cover. Our model detected true changes where forest damage was caused by selective cutting, clearcutting, pest outbreak, and forest fires while canopy closure gain was caused by some agricultural operations such as the cultivation of hazelnuts and orchards (Fig. S3, Fig. S4). Our model detected $61.3 \%$ of the test plots, while that of GFW detected $14.8 \%$ of the test points (Fig. 4). Tab. S3 in Supplementary material contains gridded estimates of and changes in canopy closure during the study period throughout the country of Georgia.

\section{Discussion}

In our study, the magnitude of the canopy closure was the best forest cover measure accounted for by the Sentinel-2 spectral data that were topographically corrected using the Minnaert Correction. Spectral bands best explaining the canopy closure were Band 3 (Green), Band 8 (NIR) and Band 12 (SWIR).

The best performance of the canopy closure in relation to satellite spectral data was expected because fisheye photographs rather than the other tree stand parameters show how much light per area is reflected and absorbed by vegetation cover. We tested 67 spectral predictors (10 Sentinel bands and 57 vegetation indices derived from these bands - Tab. S1 in Supplementary material). Out of these 67 predictors our cross-validation procedure suggested that only the three were sufficient to account quite accurately for changes in canopy closure. The importance of NIR and SWIR was not surprising because NIR and
SWIR are widely used to estimate green biomass and detect changes in vegetation density. In agreement with our findings SWIR, in contrast to NIR, was shown to have lower values for larger canopy closure and greater vegetation density (Gao 1996, Kennedy et al. 2010, Lehmann et al. 2013, Pickell et al. 2016). As for the negative response of the canopy closure to Band 3 (Green) other studies also showed that green biomass had the strongest negative correlation with reflectance in the green band of all visible wavebands (Lorenzen \& Jensen 1988). Umarhadi et al. (2018) also found the negative correlation between Sentinel B3 and canopy closure measured using hemispherical photography. The green band might also act as a variable that best minimizes shade fraction or saturation effects on NIR and SWIR. The vegetation indices, especially NDVI, performed poorly probably because they asymptotically approach the saturation in dense vegetation or high canopy regions (Tucker 1977, Gitelson et al. 2003). Sentinel-2 imagery topographically processed through the Minnaert Correction resulted in more accurate models than those based on the Cosine Correction, the Normalization method and the Senzcor-correction. This is in agreement with some other studies (Fan et al. 2018).

Our GAM-fitted canopy closure model predicts much higher values than the observed ones for some areas, where there are few or no trees. This is probably due to the fact that we underestimated the lightabsorbing power of some non-tree low vegetation such as Rubus caucasicus and subalpine meadows sparsely scattered with low birch trees. Most of our model errors are probably accounted for by the coarser DEM being used to minimize topographic effects on Sentinel-2 spectral reflectance values.

Some land surface features (e.g., high corn fields, deep water bodies, some wetlands mostly dominated by Carex spp. and orchards) showed fisheye values as high as forests (up to $80 \%$ ). This error is especially noticeable on the northern slopes of alpine meadows where Rhododendron caucasicum and stunted birch trees are distributed. This is because (i) some of these cover types are dense and tall enough to have a large shade fraction or (ii) their spectral signatures were not covered in our sample. However, these problematic features were masked out by the NFA forest cover. We also noticed that the models of topographic correction tested have a different impact on forest types, for example, in more rugged areas the canopy closure of deciduous trees was better explained than that of coniferous trees. Perhaps, steep slopes with dark coniferous trees darken the area on the image, which, in turn, distorts the process of topographic normalization. Sentinel-2 acquisition date and place, as well as difference in time between sampling tree stand parameters and Sentinel image acquisition, did not have a considerable effect on model accuracy; that makes our model reasonably robust. Although our model of loss/gain of canopy closure in the forest has reasonable predictive power, this study raises questions related to the improvement of methods for topographic correction for highly rugged terrain with regard to classifying and quantifying vegetation cover.

Our model performed much better on the test points than that of GFW. Our model detected $61.3 \%$ of the test plots, which is 
not as high as we expected. However, this can be explained by the fact that the test plots were identified using the number of trees removed from the plot whereas our model is actually designed to measure canopy closure that is a function of not only the number of trees, but also their sizes and taxonomic identity. GFW is an online near real-time monitoring and alert system, which uses Landsat imagery and powerful computational resources to detect annual changes in forest cover at the planetary scale. However, despite the impressive results of the determination of annual changes in forests, the GFW has a limitation associated with the spatial resolution of the Landsat imagery. The loss of tree cover on GFW maps shows the complete removal of a canopy of tree cover at a resolution of $30 \times 30$ meters (GFW - Hansen et al. 2013) which is not enough to monitor forests where degradation is mainly caused by selective logging or other changes at a finer scale.

\section{Conclusion}

As far as we know, this is the only model of tree loss and gain obtained through a cost-effective approach to the exhaustive analysis of reflectances and many indices that were derived from Sentinel-2 data. Cost-effective approaches in the future should play an important role in monitoring the forests of countries with low economic indicators. There are quite a few models specifically designed to assess the loss of trees and forest degradation. There are also many instruments and methodologies for measuring forest structures and parameters, but they are not always costeffective since the development of a monitoring system can be costly. Our main goal was to test the possibility of creating a system for detecting the loss of forest cover in highly rugged terrain and diverse vegetation cover of the Caucasus based on free Sentinel-2 satellite data and free software applications. For field work, we used the simplest devices, including non-professional "fisheye" lenses for mobile phones. The sample size was also minimal. We believe that models created using open source applications in combination with cheap gadgets in the future will change the rules of the game and greatly facilitate the assessment and management of natural resources. We think our model is able to reasonably detect spatial and temporal changes in forest cover, and it has potential to be improved to the extent that it can be applied by managers of natural resources in particular by wildlife managing and forestry agencies.

\section{Acknowledgements}

We would like to thank Alexander Giorgadze, David Gelashvili, Giorgi Janashvili for helping during field measurements and Nutsa Megvinetukhutsesi for assisting in mapping. Financial support was provided by World Resources Institute in the frame- work of Global Forest Watch, and by UNEP/ GEF. We would also like to acknowledge the useful comments and suggestions of two anonymous reviewers.

\section{Declaration of interest}

The authors certify that they have no affiliations with or involvement in any organization or entity with any financial interest (such as honoraria; educational grants; participation in speakers' bureaus; membership, employment, consultancies, stock ownership, or other equity interest; and expert testimony or patent-licensing arrangements), or non-financial interest (such as personal or professional relationships, affiliations, knowledge or beliefs) in the subject matter or materials discussed in this manuscript.

\section{References}

Achard F, DeFries R, Eva H, Hansen M, Mayaux P, Stibig HJ (2007). Pan-tropical monitoring of deforestation. Environmental Research Letters 2: 045022. - doi: 10.1088/1748-9326/2/4/045022

Asner GP, Keller M, Lentini M, Merry F, Souza C (2009a). Selective logging and its relation to deforestation. Geophysical Monograph Series 186: 25-42. - doi: 10.1029/2008GM000722

Asner GP, Knapp D, Balaji A, Páez-Acosta B (2009b). Automated mapping of tropical deforestation and forest degradation: CLASlite. Journal of Applied Remote Sensing 3: 033543. - doi: 10.1117/1.3223675

Brusa A, Bunker DE (2014). Increasing the precision of canopy closure estimates from hemispherical photography: blue channel analysis and under-exposure. Agricultural and Forest Meteorology 195-196: 102-107. - doi: 10.1016/j. agrformet.2014.05.001

Chianucci F, Cutini A (2012). Digital hemispherical photography for estimating forest canopy properties: current controversies and opportunities. iForest - Biogeosciences and Forestry 5: 290-295. - doi: 10.3832/iforo775-005

Chopping M, North M, Chen JQ, Schaaf CB, Blair JB, Martonchik JV, Bull MA (2012). Forest canopy cover and height from MISR in topographically complex Southwestern US landscapes assessed with high quality reference data. IEEE Journal of Selected Topics in Applied Earth Observations and Remote Sensing 5: 4458. - doi: 10.1109/jstars.2012.2184270

Civco DL (1989). Topographic normalization of Landsat thematic mapper digital imagery. Photogrammetric Engineering and Remote Sensing 55: 1303-1309.

Crowther TW, Glick HB, Covey KR, Bettigole C, Maynard DS, Thomas SM, Smith JR, Hintler G, Duguid MC, Amatulli G, Tuanmu MN, Jetz W, Salas C, Stam C, Piotto D, Tavani R, Green S, Bruce G, Williams SJ, Wiser SK, Huber MO, Hengeveld GM, Nabuurs GJ, Tikhonova E, Borchardt P, Li CF, Powrie LW, Fischer M, Hemp A, Homeier J, Cho P, Vibrans AC, Umunay PM, Piao SL, Rowe CW, Ashton MS, Crane PR, Bradford MA (2015). Mapping tree density at a global scale. Nature 525 (7568): 201-205. - doi: 10.1038/nature14967

Curtis PG, Slay CM, Harris NL, Tyukavina A, Hansen $M C$ (2018). Classifying drivers of global for- est loss. Science 361: 1108-1111. - doi: 10.1126/sci ence.aau3445

Fan W, Li J, Liu Q, Zhang Q, Yin G, Li A, Zeng Y, Xu B, Xu X, Zhou G, Du H (2018). Topographic correction of forest image data based on the canopy reflectance model for sloping terrains in multiple forward mode. Remote Sensing 10: 717. - doi: 10.3390/rs10050717

Fournier RA, Mailly D, Walter JMN, Soudani K (2003). Indirect measurement of forest canopy structure from in situ optical sensors. In: "Remote Sensing of Forest Environments" (Wulder MA, Franklin SE eds). Springer, Boston, MA, USA, pp. 77-113.

Frazer GW, Canham CD, Lertzman KP (1999). Gap Light Analyzer (GLA), version 2.0: imaging software to extract canopy structure and gap light transmission indices from true-color fisheye photographs. Simon Fraser University, Burnaby, BC, and the Institute of Ecosystem Studies, Millbrook, New York, USA. [online] URL: http://www.sfu.ca/rem/forestry/downloads/gap -light-analyzer.html

Gao Y, Zhang W (2009). A simple empirical topographic correction method for ETM+ imagery. International Journal of Remote Sensing 20: 2259-2275. - doi: 10.1080/01431160802549336

Gao B (1996). NDWI - a normalized difference water index for remote sensing of vegetation liquid water from space. Remote Sensing of Environment 58: 257-266. - doi: 10.1016/s0034-42 57(96)00067-3

Gitelson A, Gritz Y, Merzlyak M (2003). Relationships between leaf chlorophyll content and spectral reflectance and algorithms for non-destructive chlorophyll assessment in higher plant leaves. Journal of Plant Physiology 160: 271-282. - doi: 10.1078/0176-1617-00887

Goyal SK, Seyfried MS, Neill PE (1998). Effect of digital elevation model resolution on topographic correction of airborne SAR. International Journal of Remote Sensing 19: 30753096. - doi: 10.1080/014311698214190

Halperin J, LeMay V, Coops N, Verchot L, Marshall P, Lochhead K (2016). Canopy cover estimation in Miombo woodlands of Zambia: comparison of Landsat OLI versus RapidEye imagery using parametric, nonparametric, and semiparametric methods. Remote Sensing of Environment 179: 170-182. - doi: 10.1016/j.rse.20 16.03 .028

Hansen MC, DeFries R, Townshend JR, Sohlberg R, Dimiceli C, Carroll M (2002). Towards an operational MODIS continuous field of percent tree cover algorithm: examples using AVHRR and MODIS data. Remote Sensing of Environment 83: 303-319. - doi: 10.1016/s0034-4257(02) 00079-2

Hansen MC, Egorov A, Roy DP, Potapov P, Ju J, Turubanova S, Loveland TR (2010). Continuous fields of land cover for the conterminous United States using Landsat data: first results from the Web-Enabled Landsat Data (WELD) project. Remote Sensing Letters 2: 279-288. doi: 10.1080/01431161.2010.519002

Hansen MC, Potapov PV, Moore R, Hancher M, Turubanova SA, Tyukavina A, Thau D, Stehman SV, Goetz SJ, Loveland TR, Kommareddy A, Egorov A, Chini L, Justice CO, Townshend JRG (2013). High-resolution global maps of $21^{\text {st }}$-century forest cover change. Science 342: 850-853. 
- doi: 10.1126/science.1244693

Hijmans RJ (2016). Raster: geographic data analysis and modeling. R package version 2.5-8. [online] URL: http://CRAN.R-project.org/packa ge=raster

Kawata Y, Ueno S, Kusaka T (1988). Radiometric correction for atmospheric and topographic effects on Landsat MSS images. International Journal of Remote Sensing 9: 729-748. - doi: 10.1080/01431168808954889

Kennedy RE, Yang Z, Cohen WB (2010). Detecting trends in forest disturbance and recovery using yearly Landsat time series: 1 . LandTrendr temporal segmentation algorithms. Remote Sensing of Environment 114: 2897-2910. - doi: 10.1016/j.rse.2010.07.008

Korhonen L, Saputra DH, Packalen P, Rautiainen $M$ (2017). Comparison of Sentinel-2 and Landsat 8 in the estimation of boreal forest canopy cover and leaf area index. Remote Sensing of Environment 195: 259-274. - doi: 10.1016/j.rse. 2017.03.021

Köhl M, Baldauf T, Plugge D, Krug J (2009). Reduced emissions from deforestation and forest degradation (REDD): a climate change mitigation strategy on a critical track. Carbon Balance and Management 4: 10. - doi: 10.1186/1750-068 0-4-10

Lehmann EA, Wallace JF, Caccetta PA, Furby SL, Zdunic K (2013). Forest cover trends from time series Landsat data for the Australian continent. International Journal of Applied Earth Observation 21: 453-462. - doi: 10.1016/j.jag.2012. 06.005

Liang S (2005). Topographic correction methods. In: "Quantitative Remote Sensing of Land Surfaces" (Kong JA eds). John Wiley and Sons, Hoboken, NJ, USA, pp. 231-245. - doi: 10.1002/ 047172372 X.ch7

Lorenzen B, Jensen A (1988). Reflectance of blue, green, red and near infrared radiation from wetland vegetation used in a model discriminating live and dead above ground biomass. New Phytologist 108: 345-355. - doi: 10.111 1/j.1469-8137.1988.tb04173.x

Meyer LH, Heurich M, Beudert B, Premier J, Pflugmacher D (2019). Comparison of Landsat8 and Sentinel-2 data for estimation of leaf area index in temperate forests. Remote Sensing 11: 1160. - doi: $10.3390 /$ rs11101160

Pickell PD, Hermosilla T, Frazier RJ, Coops NC, Wulder MA (2016). Forest recovery trends derived from Landsat time series for North American boreal forests. International Journal of Re- mote Sensing 37: 138-149. - doi: 10.1080/215070 4X.2015.1126375

QGIS Development Team (2019). QGIS Geographic Information System. Open Source Geospatial Foundation Project, Web site. [online] URL: http://qgis.osgeo.org

R Core Team (2018). R: a language and environment for statistical computing. R Foundation for Statistical Computing, Vienna, Austria. [online] URL: http://www.R-project.org

Schleppi P, Paquette A (2017). Solar radiation in forests: theory for hemispherical photography. In: "Hemispherical Photography in Forest Science: Theory, Methods, Applications" (Fournier RA, Hall RJ eds). Series "Managing Forest Ecosystems". Springer, Netherlands, pp. 15-52.

Sexton JO, Noojipady $P$, Song $X-P$, Feng $M$, Song D-X, Kim D-H, Anand A, Huang C, Channan S, Pimm SL, Townshend JR (2015). Conservation policy and the measurement of forests. Nature Climate Change 6: 192-196. - doi: 10.1038/nclima te2816

Smith JA, Lin TL, Ranson KJ (1980). The Lambertian assumption and Landsat data. Photogrammetric Engineering and Remote Sensing 46: 1183-1189.

Tan B, Masek JG, Wolfe R, Gao F, Huang C, Vermote E, Sexton JO, Ederer G (2013). Improved forest change detection with terrain illumination corrected Landsat images. Remote Sensing of Environment 136: 469-483. - doi: 10.1016/ j.rse.2013.05.013

Teillet PM, Guindon B, Goodenough DG (1982). On the slope-aspect correction of multispectral scanner data. Canadian Journal of Remote Sensing 8: 84-106. - doi: 10.1080/07038992.198 2.10855028

Tucker CJ (1977). Asymptotic nature of grass canopy spectral reflectance. Applied Optics 16: 1151-1156. - doi: 10.1364/AO.16.001151

Umarhadi DA, Danoedoro P, Wicaksono P, Widayani P, Nurbandi W, Juniansah A (2018). The comparison of canopy density measurement using UAV and hemispherical photography for remote sensing based mapping. In: Proceedings of the " 4 th International Conference on Science and Technology". Yogyakarta (Indonesia) 7-8 Aug 2018. Institute of Electrical and Electronics Engineers - IEEE, IEEEXplore, pp. 1-5. doi: 10.1109/ICSTC.2018.8528670

Warnes GR, Bolker B, Lumley T (2015). gtools: various $R$ programming tools. $R$ package version 3.5.o. [online] URL: http://CRAN.R-project. org/package=gtools
Weston S (2017). foreach: provides foreach looping construct for $\mathrm{R}$. R package version 1.4.4. [online] URL: http://CRAN.R-project.org/pack age=foreach

Weston S (2018). doParallel: foreach parallel adaptor for the "parallel" package. R package version 1.0.14. [online] URL: https://cran.r-proj ect.org/web/packages/doParallel/index.html Wood SN (2011). Fast stable restricted maximum likelihood and marginal likelihood estimation of semiparametric generalized linear models. Journal of the Royal Statistical Society: Series B (Statistical Methodology) 73: 3-36. - doi: 10.1111/ j.1467-9868.2010.00749.x

\section{Supplementary Material}

Fig. $\mathbf{S} \mathbf{1}$ - The density curves of residuals of the canopy closure (FEYE) fitted to Sentinel reflectance values topographically corrected using four different methods.

Fig. S2 - The histogram of residuals of the canopy closure (FEYE) fitted to Sentinel reflectance values topographically corrected using Minnaert Correction.

Fig. S3 - Modeled canopy closure (FEYE) in eastern Georgia (at left) and statistically significant differences in the canopy closure in percentage at two sites between July 1, 2018 and August 5, 2016.

Fig. S4 - Modeled canopy closure (FEYE) in central Georgia (at left) and statistically significant differences in the canopy closure in percentage at two sites between Aug 28, 2018 and Aug 14, 2015.

Tab. S1 - List of the variables used for modeling forest cover.

Tab. S2 - The accuracy of the best fit GAM models for forest cover measures based on Minnaert-corrected Sentinel bands and family.

Tab. S3 - Forest stand data.

Appendix 1 - The main $\mathrm{R}$ codes used in the study.

Link: Mikeladze_3386@supplo01.pdf Link: Mikeladze_3386@supplo02.xlsx 